\title{
Can Aid Switch Gears to Respond to Sudden Forced Displacement? The Case of Haut-Uélé, DRC
}

\author{
Katharine Derderian and Liesbeth Schockaert
}

\begin{abstract}
:
How does the aid system respond when insecurity and sudden forced displacement occur in what has long been considered a stable, development context? Can longer-term aid interventions adapt when challenged to "shift gears" to address acute needs resulting from forced displacement? Based on observations from Médecins Sans Frontières projects in Haut-Uélé in northeastern DRC in 2008-2009, this article examines assistance to displaced populations and the residents hosting them in LRA-affected areas-above all, the stakes and dilemmas involved in responding to such a sudden-onset emergency in what international donors and the national government considered an area in development.

Initially, a much-needed response to violence and displacement failed to materialize, with little permanent humanitarian presence on the ground, while development approaches failed to adapt and meet emergency needs. Short-term contingency support was provided through development NGOs, but with limited scope and maintaining cost-recovery schemes for health toward an impoverished population facing an increasingly precarious situation. A long-term development approach was simply unable to respond to the sudden population increase and a fragile health situation.
\end{abstract}

\section{Résumé}

Comment réagit le système d'aide lorsque l'insécurité et le déplacement forcé soudain se manifestent dans un contexte qui a longtemps été considéré comme stable et propice au développement? L'intervention humanitaire à long terme peut-elle s'adapter quand il lui faut "changer de vitesse " pour répondre aux besoins aigus résultant des déplacements forcés? S’appuyant sur l'étude de projets de Médecins Sans Frontières dans le Haut-Uélé, dans le nordest de la RDC en 2008-2009, cet article examine l'aide aux populations déplacées et aux résidents qui les accueillent en zones touchées par l'Armée de résistance du Seigneur (LRA), plus particulièrement les enjeux et dilemmes liés à la réaction envers une situation d'urgence apparue soudainement dans une zone que les donateurs internationaux et le gouvernement national considéraient comme une zone de développement.

Au départ, une réponse fort nécessaire à la violence et au déplacement ne s'est pas concrétisée, avec une faible présence humanitaire permanente sur le terrain, alors que les approches de développement n'ont su s'adapter et répondre aux besoins d'urgence. Des ONG de développement ont apporté un soutien d'urgence à court terme mais de portée limitée et le maintien d'un système de recouvrement des coûts pour les régimes de santé à l'intention d'une population appauvrie confronté à une situation de plus en plus précaire. Une approche de développement à long terme était tout simplement incapable de répondre à l'augmentation soudaine de la population et une situation de santé précaire. 
$\mathrm{W}$ herever they occur, forced displacement and the urgent needs that result call for an immediate response. But how does the aid system respond when insecurity and forced displacement occur in what has long since been considered a stable, "development" context? Can longer-term aid interventions adapt when challenged to "shift gears" to address acute needs resulting from sudden, forced displacement?

Much has been debated about how to define humanitarian and development approaches and how to transition between or link up emergency relief and development aid in response to crises. ${ }^{1}$ Ideas of linking humanitarian and development paradigms and practices are based on several fundamental assumptions, including: the possibility for aid to treat the root causes of conflict or violence and/or to reinforce security; the nature of emergency as a temporary and transitory state; the desire to avoid "doing harm"2 and/or creating aid dependency; ${ }^{3}$ and the ability to join up humanitarian, development, political, military, and/or other objectives without diminishing the effectiveness and impact of each. Most of these assumptions have been sorely tested in recent years in an increasing number of protracted crises and fragile post-conflict settings-often highlighting the necessity of distinction between coexisting humanitarian and development approaches and challenging the idea of a linear continuum between relief and development. ${ }^{4}$

Indeed, the two approaches are divergent in their scope and aspirations. As a rule, humanitarian aid aims to meet urgent needs resulting from events that represent a rupture from normalcy, such as wars, violence, natural catastrophes, epidemics, and structural crises. Humanitarian aid adopts an immediate, politically unconditioned approach that facilitates the safe provision of assistance to those in need; it aspires to gain acceptance and security for its activities by maintaining strict principles of impartiality and neutrality. ${ }^{5}$ By contrast, development approaches privilege ongoing, sustainable advances toward ending poverty and achieving human security. While humanitarian aid focuses on the immediate needs of populations, development aid rather emphasizes support to systems in the longer term. This means that development can align itself with wider political objectives, including peace-building, state-building, and/or reinforcement of human rights and governance. In practice, the two paradigms of humanitarianism and development are often hardly absolutely distinct, with field-level situations often ending up between emergency and development poles, with both paradigms coexisting-depending on varying security, political, and economic conditions, as well as the functioning of basic services. At present, the tensions between the two approaches are thrown into even greater relief in an era when aid aspires to transition smoothly from crisis response to state-building, often in volatile post-conflict settings. ${ }^{6}$ Accepting any reversal of development gains and the resurgence of emergency needs defies the conventional logic of a linear transition from humanitarian to development response.

In health and humanitarian assistance, several key issues around humanitarian and development approaches recur regularly in practice. ${ }^{7}$ How to reconcile the two approaches and/or manage transition between the two approachesfrom humanitarian to development, but also development to emergency, if need be? What is the real practicability and effectiveness of linking humanitarian and development and/ or adopting "early recovery" approaches? How to ensure an immediate response to urgent needs despite the often political demands for sustainability of longer term projects? In areas where humanitarian and development projects coexist, how to ensure respect of the operationally indispensable humanitarian principles that guarantee security and access - while in exactly the same context, development aid may legitimately align with state structures or adopt political objectives?

Sudden forced displacement adds another challenge to these already classic discussions. Concerns about sustainability suddenly come into tension with an urgent need for immediate assistance to cover the most basic needs of moving populations. Aid is challenged to "switch gears" from development to an emergency response-this has been exactly the case in Haut-Uélé in northeastern DRC in 2008-2009.

The remote and sparsely populated regions of Haut-Uélé and Bas-Uélé in Orientale Province have long been one of the most marginalized, if peaceful, areas in DRC, suffering from extremely fragile infrastructure and inadequate, often non-existent basic services-with no permanent international aid presence on the ground. Starting in September 2008, civilians in the Uélés were caught up in attacks by the Ugandan rebel group the Lord's Resistance Army (LRA), as well as in clashes between the LRA and the Congolese army and other regional armies. ${ }^{8}$ As the situation deteriorated, civilians also found themselves facing increasing banditry. Thousands of displaced people fled to seek shelter and greater security in towns like Dungu, Doruma, Niangara, and Faradje that grew into ever more populous enclaves, with outlying villages and fields empty and often insecure.

With LRA presence throughout the larger region, violence and armed confrontations gradually expanded, impacting not only Haut-Uélé and Bas-Uélé in northeastern DRC, but also neighbouring areas of southern Sudan ${ }^{9}$ and eastern Central African Republic. Both internal displacement and refugee flows became widespread in an otherwise sparsely populated region. As of October 2010, the UN estimated 2,000 people had been killed, over 2,600 abducted, 
and over 400,000 displaced in these three countries. Some 268,000 people remain displaced in northeastern DRC, over 120,000 in Western Equatoria in southern Sudan, and 30,000 in southeastern Central African Republic. ${ }^{10}$ From January to mid-March 2011, the UN reports 35 people killed, 104 abducted, and over 17,000 displaced in LRA-affected areas of Orientale Province. Since 2008, 20,000 Congolese have sought refugee in southern Sudan, while 3,500 have fled to Central African Republic. ${ }^{11}$ By contrast to some refugees who have been housed in camps (e.g. Makpandu and Ezo in southern Sudan), ${ }^{12}$ most internally displaced find themselves seeking shelter with local populations and sharing already scarce resources in order to survive.

Since January 2009, Médecins Sans Frontières (MSF) has intervened in response to the violence and displacement in the Uélés and currently runs medical humanitarian projects in Dingila, Doruma, Dungu, Duru, and Niangara. In these locations, MSF projects offer primary and secondary health care free of charge, with a strong mobile outreach component wherever access allows (e.g. mobile clinics to the outlying areas of Nambia and Tapili from Niangara), or evacuations of wounded from Bangadi to Dungu by plane. Drawing on assessments in the region, interviews with international and Congolese health care providers and ongoing work within MSF projects in the field, this article examines assistance to displaced populations and the residents hosting them in LRA-affected areas in northeastern DRC. The case of Haut-Uélé provides insight into some of the key stakes and dilemmas involved in responding to such a sudden-onset emergency in what international donors and the national government considered an area in development to date.

The sudden violence, displacement, and urgent need in the Uélés challenged ongoing development in the region to adapt and "shift gears"- to respond to immediate, often life-saving needs; to negotiate between ongoing development programming and emergency response; to build on years of lessons learned about assisting mixed populations of newly displaced and residents facing shared vulnerability; to suspend conditioning of aid or concerns of sustainability to provide timely and unconditional humanitarian assistance during a period which could last for the medium or even longer term. Considering a case of "shifting gears" as in Haut Uélé is paramount for aid practitioners and policy-makers facing ever more crises where humanitarian and development strategies coexist-and yet also aiming to meet the ambition to provide timely, effective, and meaningful aid for those in need.

At the onset of displacement in the Uélés, sparse development funding was provided to this isolated and fragile region in the form of drug kits and financial incentives for medical staff in selected health structures. This support was already only partial, and provided without direct supervision. In some places, drug kits contained no first-line malaria medication in an endemic region, yet did contain heart medication requiring diagnostic tests not available in local health centres. Staff incentives were not complemented by any funding for maintenance of health structures themselves. In a cost recovery scheme, patients had long paid for the very basic health care accessible only at the few functional facilities in the region.

Faced with an emergency displacement situation, yearlong development schemes already in these zones de santé found themselves struggling to keep up with more acute needs and spikes in consultations. In already fragile outlying health structures, staff responded to the insecurity by fleeing and/or reducing services even on the periphery of larger towns. One health centre outside a large town ended night service, in-patient care, and deliveries in December 2008 in order to avoid staff and patient presence inside the structure and their resulting exposure to possible violence.

With the arrival of the LRA, the unexpected influx of IDPs confronted an already sparse landscape of development NGOs in the region. At the same time, due to insecurity and inaccessibility of the area, few other humanitarian organizations responded in the immediate aftermath. Absolutely no UN humanitarian funding was allotted for the emergency in Haut-Uélé until mid-year 2009.13 Even with increased attention to the Uélés, as of late 2009, there was a striking absence of NGOs permanently in the field outside the regional hub of Dungu. ${ }^{14}$ While both humanitarian and development donors did recognize the emergency in late 2008, development actors expressed concern to MSF that an emergency intervention could "destabilize" ongoing development efforts. With an eye to the longer term development in course, donors responded with shortterm contingency programs of three to six months, often specifically targeting IDPs with free health care.

Yet in the situation of shared vulnerability for both IDPs and residents hosting them, local health care staff were faced with the dilemma of imposing fees on some patients while offering others free care. ${ }^{15}$ Various national and international actors registered vastly different numbers of IDPs, causing difficulty in assessing needs and identifying IDPs, who in fact shared the same fragile living conditions as the host population. Short-term contingency plans caused practical confusion between free medications for IDPs under the emergency response, and for-charge medications under the prior long-term scheme. In the end, the overwhelming influx of new, displaced patients led to key medications being out of stock and to an overall decline in ability to care for people in this precarious time. 
Below are two examples of how the challenge of "shifting gears" played out in the Uélés at the time. In one key town, the local population in a territory of some 92,500 residents faced an influx of 25,000 displaced people. Residents and IDPs shared all resources and consequently experienced a general decline in living conditions for all inhabitants together, along with the ongoing insecurity. At the outset of the emergency, the development NGO working in the zone received international funding for some 2.5 months from November 2008 to February 2009, to cover IDP needs with pre-positioned drug kits. These soon ran out, causing problems for personnel to explain to patients the reintroduction of fees for services and medications. The town's reference hospital offered no more than 850 consultations per month to patients in late 2008-early 2009. Yet, as international contingency support to the hospital ended in February, overall consultations dropped to fewer than 500 per month in March 2009.

In another key town affected by the violence in late December 2008, 93,000 residents saw the displacement of some 22,000 people in the surroundings and an influx of at least 5,000 people into the town by April 2009. The first distribution of food aid took place in early April 2009, but no household items were provided to the displaced nor were any provided to residents, 690 of whose houses had been burned. The small local reference hospital and several health centres had been supported by development aid funding since 2000, providing medical care on a for-fee basis. Emergency funding for this location did not become available until April 2009 and only lasted for six months, covering solely primary health care (without renovation or equipment of structures, e.g. with waste areas) and reimbursing consultation fees to pay staff (but only based on the new patient caseload). This funding provided for free medical care to all patients only in two key towns, based on their being "more affected" by the insecurity, while in other towns in the region, only IDPs received free medical care. In the end, the combination of emergency and development funding covered all medical costs in some cases, but hardly represented a solution to widespread needs.

A related and similarly complex debate arose in the Uélés around the idea of "do no harm," shared by both humanitarian and development actors. Out of well-founded concerns that aid provided to displaced communities could make them a target for looting or attacks by various armed actors, UN forums at field level discussed criteria for stepping up assistance in mid-2009. Yet preconditions considered for the provision of aid included very political considerations entirely out of place in an emergency context: the attitude of the local authorities toward controlling and benefiting from aid, the discipline and material provision for the national army, FARDC, and the presence of IDP self-representation and registration. Due to the lack of international humanitarian aid, IDPs regularly travelled into insecure areas to recover food or other resources from their abandoned houses, villages, or fields. In an informal survey done in two IDP sites in a large town in Haut Uélé in July 2009, 32 per cent and 66 per cent in each site said they had gone back to their home communities to try to recover food or other items; by contrast, the overwhelming majority expressed no intention in returning to their homes on a permanent basis. The upshot of this debate was that an ostensible concern for protection and longer-term sustainability of the overall aid intervention effectively minimized an emergency intervention, conditioning assistance on behaviour and governance by civil and military authorities. The risks linked with distributing aid had effectively been transferred to the IDPs themselves, who undertook the dangerous travel back to their abandoned homes to cope when international assistance failed to arrive.

At the same time, ironically, there was an overwhelming absence of (inter)national actors working on protection, in particular working on sexual violence and child protection, key issues often cited in connection with the LRA context. The initially meager physical presence of humanitarians in the field, while providing some (material) support to the population, remained hampered by insecurity and was hardly enough to ensure protection, much less to provide for even basic needs. ${ }^{16}$

Today, in the Uélés, widespread insecurity persists, giving IDPs little chance to return to outlying villages and fields. Perceived as safer, towns have attracted ever more displaced people seeking security and evolved ever more into enclaves. As of mid-year 2010, the population had surged in towns like Niangara, which doubled to 40,000 inhabitants due to the influx of displaced people. The situation in Niangara and throughout the Uélés poses the question of how assistance will continue in future-with continued insecurity, the lack of an immediate solution for the displaced, and the precarious situation shared by both residents and IDPs who depend on a handful of emergency aid actors for their most basic needs.

Response to displacement in the Uélés raises several key issues. To what extent is it acceptable to delay or limit emergency response because a region of forced displacement has long been characterized as being in "development"? How long can an emergency response depend solely on ad hoc approaches and contingency plans in the short term, while still holding onto the idea of preserving the sustainability of long-term programs? To what extent can long-term intentions ever legitimately take precedence over short-term, lifesaving responses to urgent humanitarian needs? Keeping in 
mind the contrast with the few refugee camps established in the region, can "targeting" IDPs in mixed populations ever be acceptable in a humanitarian response to forced displacement, where displaced share the living conditions of host families?

In Haut-Uélé, ad hoc contingency responses were advanced to address a sudden-onset emergency in the interest of maintaining ongoing development work. The upshot of this approach included delays and gaps in assistance as well as inaccessible and often inadequate medical care in an emergency situation. Faced with large-scale violence and displacement with probable longer-term impact, such an approach risks reaching neither humanitarian nor development objectives-neither meeting urgent needs nor assuring access to health care for an entire community facing heightened and shared vulnerability. Forced displacement and violence may reverse desirable development gains, but the broader policy and often political goal of ensuring their sustainability cannot come at the very real cost of neglecting a life-saving response.

For the first year after the arrival of the LRA, aid in the Uélés remained absolutely inadequate in response to the needs of this mixed population of newly displaced and residents facing shared vulnerability and widespread violence. A much-needed, timely humanitarian response to violence and displacement failed to materialize, with an almost absolute lack of permanent humanitarian presence on the ground, as well as political conditioning of urgent emergency assistance on questions of governance and protection. At the same time, development approaches failed to adapt and meet emergency needs. So as not to disturb long-term efforts, short-term contingency support was provided through development NGOs, but with limited scope in time and place and maintaining cost-recovery schemes for health toward an already impoverished population facing an increasingly precarious situation. A development approach focused on the long term was simply unable to respond to the sudden increase in population and to their ever more fragile health situation.

The Uélés are hardly an isolated case of the challenges of responding to displacement in "development" zones of DRC - similar dilemmas have also arisen recently around displacement in Equateur. Drawing on field-based experience, this article aims to feed debates on humanitarian and development paradigms by showing how the concrete and complex dilemmas for practitioners translate into a very real impact on the lives and health of populations. Similar scenarios occur in many other contexts worldwide where sudden-onset emergencies, violence, and displacement are likely to arise alongside extensive "development" work and challenge the paradigm of a linear transition or easy coexistence of humanitarian and development aid-from Afghanistan to Haiti, southern Sudan, and Ivory Coast. The aid system's response to emergency needs arising in "development" contexts deserves further study and elaboration to ensure the most relevant and effective assistance possible in response to urgent humanitarian needs. The many barriers to emergency response in "development" settings merit further, concrete analysis as to how they actually play out in the field. These include the frequent absence of implementing actors and/or limited funding instruments in such sudden-onset emergencies; tensions around sustainability-in particular between emergency response and wider support to (health) systems; questions around the degree of aid alignment with states that may be absent, fragile, or belligerents per se; and wider divergences in philosophies of intervention (e.g. cost recovery, "do no harm")—-just to name a few. Cases such as Haut Uélé should provoke further debate about the continually evolving coexistence of humanitarian and development strategies, as well as about divergent assistance to refugees, IDPs, and host population, particularly in open settings ${ }^{17}$ where vulnerable populations are frequently forced to share already-scarce resources and services.

While the long-debated tensions between emergency and development approaches will never be fully resolved, the presence of development aid simply cannot and should not justify the failure of a timely and meaningful response to emergency humanitarian needs. Those working on violence and forced migration are challenged to remain vigilant to ensure that longer-term concerns do not hinder the response of "shifting gears" to meet the immediate needs of displaced people.

\section{Notes}

1. For some of the key debates on humanitarianism and development, see Adele Harmer and Joanna Macrae, eds., "Beyond the Continuum: The Changing Role of Aid Policy in Protracted Crises," HPG Research Report 18 (July 2004), http://www.odi.org.uk/resources/download/236.pdf.

For the challenges of transition in health, see Ann Canavan, Petra Vergeer, and Olga Bornemisza, "Post-Conflict Health Sectors: The Myth and Reality of Transitional Funding Gaps," Health and Fragile States Network with Royal Tropical Institute Antwerp, October 2008, http:// www.healthandfragilestates.org/index2.php?option=com _docman\&task=doc_view\&gid=33\&Itemid=38. This study surveys several "post-conflict" contexts including DRC, concluding that during "transition," health services often contract as humanitarian funding for health is reduced yet inflow of development aid remains slow. The three main determinants of inadequate transitional funding for health 
were identified as: inadequate aid instruments, donor policy and priorities, and weak country governance. Even where aid instruments are adapted to transition, they do not always lead to adequate funding for health and suffer from tensions between state-avoidance and state building. For health in particular, there is often very limited tracking of aid flows within the health sector, making it difficult to assess funding gaps and to ensure health services do not contract during the crucial post-conflict period, when populations are still very vulnerable.

Also on negotiating between humanitarian and development approaches to health in DRC, see: Alain Kassa, Michel Van Herp, Mit Philips, and Frederique Ponsar, "Access to Healthcare, Mortality and Violence in Democratic Republic of Congo. Results of Five Epidemiological Surveys: Kilwa, Inongo, Basankusu, Lubutu, Bunkeya," (October 2005), http://www.doctorswithoutborders.org/publications /reports/2005/drc_healthcare_11-2005.pdf.

2. See Mary B. Anderson, "Do No Harm: How Aid Can Support Peace-or War," Boulder, CO: Lynne Rienner, 1999. Anderson's argument is that the provision of aid can either cause harm or can reinforce peace in conflict situations. As aid involves bringing resources such as food, water, and health care into a resource-poor environment, it risks causing harm and reinforcing conflict among contending groups. Anderson argues that aid can be reoriented to avoid unintended harm or support to "dividers" and maximize its positive support to "connectors" to reduce conflict.

3. For a critical look at the "aid dependency" debate for humanitarian aid, see Paul Harvey and Jeremy Lind, "Dependency and Humanitarian Relief: A Critical Analysis," HPG Research Briefing 19 (July 2005), http://www.odi.org .uk/resources/download/265.pdf.

4. See Kerry Demusz, "From Relief to Development: Negotiating the Continuum on the Thai-Burmese Border," Journal of Refugee Studies 11, no. 3 (1998): 231-44, http://jrs .oxfordjournals.org/content/11/3/231.abstract.

5. Humanitarian principles, including independence, impartiality (response solely according to need), and neutrality (not taking sides in conflicts), have practical importance for belligerents or political authorities to accept humanitarian aid and allow access for it to safely reach populations in need. These principles are drawn from international humanitarian law and are reproduced in many codes of conduct, mission statements, or charters and other policy documents of aid actors and donors. For more in-depth discussion of humanitarian principle and its vital links to practice, see e.g.: Nicolas Leader, "The Politics of Principle: The Principles of Humanitarian Action in Practice," HPG Report 2 (March 2000), http://www.odi.org.uk/resources/ download/252.pdf ; and Kate Mackintosh, "The Principles of Humanitarian Action in International Humanitarian Law," HPG Report 5 (March 2000), http://www.odi.org.uk/ resources/download/249.pdf.
For some examples of principles as viewed by practitioners, see the Red Cross/Red Crescent seven fundamental principles, http://www.ifrc.org/en/who-we-are/vision -and-mission/the-seven-fundamental-principles/, as well as MSF's charter referring to humanitarian principles, http://www.msf.org/msf/articles/2011/03/the-medecins -sans-frontieres-charter.cfm.

6. See for example Victoria Wheeler, Sue Graves, and Michael Wesley, "From Crisis Response to State-building: Services and Stability in Conflict Affected Contexts," HPG Discussion Paper (October 2006), http://www.odi.org.uk/ resources/download/608-full-paper.pdf; and Margaret E. Kruk, Lynn P. Freedman, Grace A. Anglin, and Ronald J. Waldman, "Rebuilding Health Systems to Improve Health and Promote Statebuilding in Post-conflict Countries: A Theoretical Framework and Research Agenda," Social Science and Medicine 70 (2010): 89-97, http://www.ncbi.nlm .nih.gov/pubmed/19850390.

7. Some of these issues are addressed in the following: Gorik Ooms, "Health Development vs. Medical Relief: The Illusion versus the Irrelevance of Sustainability," PLoS Medicine 3, no. 8 (2006): e345, http://www.plosmedicine.org/ article/info:doi/10.1371/journal.pmed.0030345; Wim Van Damme, Wim Van Lerberghe, and Marleen Boelaert, "Primary Health Care vs. Emergency Medical Assistance: A Conceptual Framework," Health Policy and Planning 17, no. 1 (2002): 49-60, http://heapol.oxfordjournals.org/cgi/ reprint/17/1/49.pdf; Sarah Bailey, Sara Pavanello, Samir Elhawary, and Sorcha O'Callaghan, "Early Recovery: An Overview of Policy Debates and Operational Challenges," HPG Working Paper (November 2009), http://www.odi .org.uk/resources/download/4617.pdf; Jonathan Moore, "The Humanitarian-Development Gap," International Review of the Red Cross 833 (1999): 103-07, http://www .icrc.org/web/eng/siteeng0.nsf/html/57JPT2.

8. As MSF is an independent and impartial humanitarian organization with field operations, a neutral stance toward all armed actors is paramount to its ability to securely access and assist populations in need. In keeping with our neutrality, MSF neither advances its own analysis of political and military contexts nor endorses any particular analysis conducted by others. For those readers interested in further analysis on the Lord's Resistance Army (LRA) in DRC and the regional and international responses to the LRA presence, see the following documents published by other experts and organizations: Tim Allen and Koen Vlassenroot, eds., The Lord's Resistance Army: Myth and Reality (London: Zed Books, 2010); Ronald Atkinson, "From Uganda to the Congo and Beyond: Pursuing the Lord's Resistance Army," International Peace Institute, December 2009, http://www.ipacademy.org/media/ pdf/publications/e_pub_uganda_to_congo.pdf; Ledio Cakaj, "Between a Rock and a Hard Place: LRA Attacks and Congolese Army Abuses in Northeastern Congo," Enough, March 2010, http://www.enoughproject.org/files/

(C) Katharine Derderian and Liesbeth Schockaert, 2010. This open-access work is licensed under a Creative Commons AttributionNonCommercial 4.0 International License, which permits use, reproduction and distribution in any medium for non-commercial purposes, provided the original author(s) are credited and the original publication in Refuge: Canada's Journal on Refugees is cited. 
publications/LRA_Congo_Activist_Brief.pdf; Ledio Cakaj, “The Lord's Resistance Army of Today," Enough, November 2010, http://www.enoughproject.org/files/publications/lra _today.pdf; Ledio Cakaj, “'This Is Our Land Now': Lord's Resistance Army Attacks in Bas-Uélé, Northeastern Congo," Enough, August 2010, http://www.enoughproject .org/files/publications/thisisourlandnow.pdf; Jort Hemmer and Nikki Frenken, "The Lord's Resistance Army: In Search for a New Approach," Conflict Research Unit, Clingendael Institute, June 25, 2010, http://www.clingendael.nl/ publications/2010/20100629_cru_report_jhemmer.pdf; Human Rights Watch, "The Christmas Massacres: LRA Attacks on Civilians in Northern Congo," February 16, 2009, http://www.hrw.org/node/80773; Human Rights Watch, "Trail of Death: LRA Atrocities in Northeastern Congo," March 2010, http://www.hrw.org/node/89324; IKV Pax Christi, "How EnLightning Is the Thunder? Study on the Lord's Resistance Army in the Border Region of DR Congo, Sudan and Uganda," February 2009, http://reliefweb .int/node/304512; International Crisis Group, "LRA: A Regional Strategy beyond Killing Kony," April 28, 2010, http://www.crisisgroup.org/ /media/Files/africa/horn-of -africa/uganda/157\%20LRA\%20-\%20A\%20Regional\%20 Strategy\%20beyond\%20Killing\%20Kony.ashx; Mareike Schomerus and Kennedy Tumutegyereize, "After Lightning Thunder: Protecting Communities and Building Peace," Conciliation Resources April 2009, http://www.c-r.org/our -work/uganda/documents/After_Operation_Lightning_Thunder_29April09_lores.pdf; Small Arm Survey, "The Lord's Resistance Army," March 2011, http://www.smallarmssurveysudan.org/pdfs/facts -figures/armed-groups/southern-sudan/HSBA-Armed -Groups-LRA.pdf; and Steven Spittaels and Filip Hilgert, "Mapping Conflict Motives: Province Orientale (DRC)," March 17, 2010, http://www.ipisresearch.be/maps/ Orientale/20100322_MappingOrientale.pdf.

9. In response, MSF medical staff have worked in the region since September 2008 and currently are present in Ezo, Naandi, Yambio, and Makpandu, providing assistance to around 45,000 people living in camps or integrated within host communities. For further information on the MSF response, see http://www.msf.org/msfinternational/ invoke.cfm? component $=$ article \&objectid $=\mathrm{E} 4 \mathrm{~A} 1743 \mathrm{C}$ 15C5-F00A-258A328AFE3E3FE4\&method=full_html and http://www.msf.org/msfinternational/invoke.cfm?objectid $=\mathrm{E} 9605 \mathrm{CD} 6-15 \mathrm{C} 5-\mathrm{F} 00 \mathrm{~A}-2$ 5CB 6 E B 6 B 3 B A F 948 \&component=toolkit.article\&method=full_html.

10. "UNHCR Seeing New Displacement Caused by Lord's Resistance Army," briefing notes, October 15, 2010, http:// www.unhcr.org/4cb832c29.html.

11. UNHCR, "New LRA Attacks against Populated Areas of Northeastern Democratic Republic of the Congo," March 1, 2011, http://www.unhcr.org/refworld/country,",' COD,,4d6ceecf2,0.html.
12. At least since the 1990s, a lively debate has centred around the dilemmas of the relatively expedient provision of aid to refugees and IDPs in camps as opposed to open settings-see e.g. Richard Black, "Putting Refugees in Camps" and Barbara Harrell-Bond, "Camps: Literature Review," in Forced Migration Review 2 (1998), http://law.wustl.edu/Library/cdroms/refugee/data/ FMR\%5CEnglish\%5CFMR02\%5Cfmr201.pdf and http:// www.fmreview.org/FMRpdfs/FMR02/fmr206.pdf respectively, as well as Jeff Crisp and Karen Jacobsen, "Refugee Camps Reconsidered," Forced Migration Review 3 (December 1998), http://www.fmreview.org/FMRpdfs/FMR03/ fmr307.pdf.

Still, one key point of consensus is the imperative to ensure that assistance provided to refugee or displaced populations should also take into account the needs of resident populations nearby, who often host refugees or IDPs themselves. This lesson learned has translated into standard practices, taking into consideration the needs of both refugee or displaced and resident populations; see e.g. UNHCR's "Handbook for Self-Reliance" (July 20, 2006) http://www.unhcr.org/44bf40cc2.html or the Sphere Project, "Humanitarian Charter and Minimum Standards in Disaster Response, http://www.sphereproject.org/component/option,com_docman/task,cat_view/gid,17/Itemid,203/ lang,english/.

13. UN planning only foresaw a humanitarian budget for the region of Haut-Uélé as of the Mid-Year Revision of the Humanitarian Action Plan 2009. See "Révision à Mi-Parcours du Plan d'Action Humanitaire 2009- RDC," page 62, http://www.rdc-humanitaire.net/IMG/pdf/MYR_2009_ DRC_HAP_FR_SCREEN.pdf.

14. MSF, "Violence Expands in Northern DRC- Population in Urgent Need of Assistance," October 14, 2009, http://www. $\mathrm{msf}$.org/msfinternational/invoke.cfm? objectid=517D655B -15C5-F00A-25C6A413A8701F11\&component=toolkit .pressrelease\&method=full_html.

15. See IASC Global Health Cluster, "Removing User Fees for Primary Health Care Services during Humanitarian Crises," March 24, 2010, http://www.who.int/hac/global_ health_cluster/about/policy_strategy/EN_final_position_ paper_on_user_fees.pdf. The World Health Organization's Global Health Cluster argues that: (1) user fees impede access to health care, typically adding to health care costs and resulting in poor and vulnerable groups not always seeking appropriate health care when needed; (2) waivers and exemption policies to deal with the negative impact of user fees often are difficult to implement; and (3) poorer households often must resort to reducing food consumption, self-medicating, and/or enduring catastrophic health expenditures to afford fees. In addition, maintenance of user fees (often prescribed by national policies) flies in the face of impartiality (i.e. needs-based approach) to aid enshrined in the humanitarian principles. For more on the debate, see also: Chris D. James, et al., "To Retain or Remove 
User Fees?: Reflections on the Current Debate in Low- and Middle-Income Countries," Applied Health Economics and Health Policy 5, no. 3 (2006): 137-53, http://adisonline .com/healtheconomics/Abstract/2006/05030/To_Retain_ or_Remove_User_Fees__Reflections_on_the.1.aspx; Ke $\mathrm{Xu}$, et al., "Household Catastrophic Health Expenditure: A Multi-country Analysis," Lancet 362 (July 2003): 111-17, http://www.who.int/health_financing/Lancet\%20paper -catastrophic\%20expenditure.pdf; Also see Timothy Poletti, "Cost-Recovery in the Health Sector: An Inappropriate Policy in Complex Emergencies," Humanitarian Exchange Magazine 26 (March 2004), http://www.odihpn.org/report .asp?id=2609. Poletti provides a critical review of the development-oriented arguments for cost recovery and the negative outcomes of imposition of user fees in emergency settings including diminished access to care, impoverishment of patients, lack of equity, and complications in programming.

For MSF field-based research on the impact of user fees on access to health care, including in DRC, see "No Cash, No Care: How 'User Fees' Endanger Health,” March 2008, http://www.msf.org.za/docs/No_cash_No_care_report_ April-2008.pdf. This study points to data from 2005 showing that 29 per cent to 38 per cent of the population in some areas of DRC (then in a phase of "reconstruction") lacked access to health care, with 35 per cent to 85 per cent of those interviewed citing lack of money as the reason for their exclusion from care.

16. Katharine Derderian and Liesbeth Schockaert, "The Limits of Humanitarian Protection: A Field-Based Perspective from an Humanitarian Organization," paper for conference "Protecting People in Conflict \& Crisis," Refugee Studies Centre, Oxford University and Humanitarian Policy Group, September 2009, http://www.rsc.ox.ac.uk/PDFs/ sessionVgroup1liesbethschorkaertandkatharinederderian .pdf.

17. On responses in open settings in the Uélés in particular, see Alena Koscalova, Elena Lucchi, and Sabine Kampmüller,
“Outside Camp Settings," Forced Migration Review 36 (November 2010), http://www.fmreview.org/DRCongo/koscalova-lucchi-kampmuller.htm.

Katharine Derderian works with the Analysis and Advocacy Unit at Médecins Sans Frontières in Brussels, Belgium. With MSF since 2001, Katharine has worked in MSF field missions in Liberia, Angola, Kenya, DRC, Haiti, and Southern Sudan. Since joining headquarters in 2005, she has focused on contexts of conflict, most recently Sudan and DRC. Katharine has a PhD in classical philology from Princeton University.

Liesbeth Schockaert is currently working as an Associate Legal Officer in UNHCR's Regional Representation for Western Europe. This article is written in a personal capacity and does not necessarily represent the views of the organization. She has also worked in the Analysis and Advocacy Unit at Médecins Sans Frontières Belgium at its headquarters in Brussels, and has a broad field experience in refugee and displacement settings inside and outside Europe. Liesbeth has an LLM in international law from Ghent University and an MSc in European and international politics from the University of Edinburgh.

This paper draws on fieldwork carried out in several locations in Haut-Uélé by the first author and by other MSF colleagues from March to July 2009_including assessments of local health structures, interviews with Congolese and international medical and humanitarian personnel and project management on the ground.

The authors wish to thank Mit Philips, Sergio Martin, Amaury Gregoire and Emmanuel Lampaert for their invaluable input. 